\title{
Dinâmicas dos sistemas agrários nos territórios mapuche de Araucanía Costera, Chile
}

\author{
Dynamics of agricultural systems in the territories mapuche de Araucanía Costera, Chile
}

\author{
Cecilia Obreque Moncada ${ }^{1}$ \\ German Catalán Nahuelcheo ${ }^{2}$ \\ Gabriela Coelho-de-Souza ${ }^{3}$
}

\section{Resumo}

A Região de Araucanía Costera, no Chile, é considerada historicamente como território dos indígenas mapuche. Nesse contexto, objetivou-se estudar a evolução e diferenciação dos sistemas agrários nos territórios mapuche de Araucanía Costera, buscando compreender as dinâmicas ocorridas. A metodologia constou de análise de imagens de satélites dos anos 1973, 1999 e 2008, além de revisão bibliográfica, na qual foram avaliados aspectos naturais do espaço, fatores históricos e político-institucionais que consolidaram as diferentes etapas do desenvolvimento da agricultura. A análise permitiu caracterizar quatro grandes sistemas agrários: indígena, pré-colonial, colonial e atual, em um período que se estende, desde muito antes de 1536, até o período atual. O processo de evolução dos sistemas agrários nessa região impôs uma dinâmica de transformação da sociedade mapuche e perda de grande parte de seus territórios, que passaram a ser utilizados para a produção de monocultivos arbóreos.

Palavras-chaves: Sistemas agrários. Araucanía Costera. Mapuche. Territórios indígenas.

\begin{abstract}
The coast region of La Araucanía in Chile is considered historically as a territory of the indigenous mapuche. In this context, the objective was to study the evolution and differentiation of the agrarian systems in the mapuche territories of La Araucanía's coast, seeking to understand the dynamics that occurred. The methodology consisted of satellite image analysis in the period from 1973, 1999 to 2008, as well as a bibliographi cal review, which evaluated the natural aspects of space, historical and political-institutionalfactorswhichconsolidatedthedifferentstages of agricultural development. The analysis allowed to characterize four great agrarian systems: indigenous, pre-colonial, colonial and current, in a period that extends, from long before 1536, until the present period. The process of evolution of the agrarian systems in this region imposed a dynamic of a transformation of the mapuche society and loss of great part of its territories. After that they used it for the production of arboreal monocultures.

Keywords: Agrarian systems. Coast Araucanía. Mapuche. Indigenous territories.

\footnotetext{
${ }^{1}$ Programa de Pós-Graduação em Desenvolvimento Rural (PGDR), da Universidade Federal do Rio Grande do Sul. E-mail: ceciliaobreque@gmail.com.

2 Laboratorio de Ecología del Paisaje Forestal. Universidad de La Frontera, Temuco, Chile. Email: german.catalan@ufrontera.cl.

${ }^{3}$ Programa de Pós-Graduação em Desenvolvimento Rural (UFRGS). E-mail: gabriela.coelho@pq.cnpq.br.
} 


\section{Introdução}

O sul do Chile sofreu mudanças no espaço geográfico desde a chegada dos espanhóis, que introduziram a agropecuária e modificaram a floresta nativa e outros espaços naturais, provocando um importante processo de alteração do território (ENDLICHER, 1988; BENGOA, 1996; DONOSO e LARA, 1997). Ao longo do tempo, essas mudanças foram aumentando juntamente com o apoio do Estado através da implementação de instrumentos de fomento ao setor silvo-agropecuário (PEÑA-CORTÉS et al., 2005).

A economia da Araucanía Costera difere em grande parte da economia camponesa em geral; o desenvolvimento do setor costeiro é caracterizado por sua diversidade, integrando produção agrícola, florestal e extração de recursos marinhos (PLADECO PUERTO SAAVEDRA, 2013). Dadas às características geográficas e do solo, existe uma gama de produção, destacando-se o trigo e, particularmente, a batata, assim como outros cultivos de aveia e horticultura, constituindo superfícies pequenas de importância no consumo familiar (PLAN REGULADOR TOLTEN, 2005; PLADECO CARAHUE, 2013).

O objetivo deste artigo foi estudar a evolução e diferenciação dos sistemas agrários nos territórios mapuche de Araucanía Costera, região de La Araucanía, no Chile, buscando compreender as dinâmicas ocorridas em seus territórios. Entende-se sistemas agrários como o resultado do aproveitamento do potencial solo-clima pelos grupos humanos; isso depende dos objetivos e variam de acordo com o meio ambiente em que estão inseridos, o tipo de sociedade, a estrutura econômica, as políticas do Estado (RIOSECO, 2016). Para Mazoyer e Roudart (2010), o estudo da transformação e diferenciação da agricultura é um instrumento intelectual que, pela análise metódica da organização e funcionamento das distintas formas históricas da agricultura, possibilita a apreensão e compreensão da sua complexidade.

$\mathrm{O}$ artigo está organizado em três seções, além desta introdução. Na primeira apresenta-se uma caracterização geral da região de La Araucanía. Na segunda parte é apresentada a evolução e diferenciação dos sistemas agrários observados na região, subdividida em quatro partes, na qual são detalhados os sistemas agrários observados, sendo eles: Indígena, Pré-colonial, Colonial e Atual. Por fim, são apresentadas as conclusões. 


\section{Metodologia}

A metodologia constou de extensa revisão bibliográfica, na qual foram avaliados aspectos naturais do espaço, fatores históricos e político-institucionais, além de socioeconômicos e culturais, que consolidaram as diferentes etapas do desenvolvimento da agricultura, buscando-se caracterizar os aspectos chaves para a compreensão da evolução e diferenciação dos sistemas agrários nos territórios mapuche de Araucanía Costera. Os períodos foram construídos a partir de uma primeira grande delimitação geral proposta por MIGUEL (2009). Procurou-se usar datas de eventos importantes na Região de La Araucanía como sinalizadoras gerais da delimitação cronológica entre os sistemas agrários. Como forma de analisar as transformações na cobertura vegetal no período atual foi realizada análise do processamento espaço-temporal de imagens de satélites dos anos 1973, 1999 e 2008, mediante o software SIG do código aberto (QGIS).

\section{Localização geográfica da Araucanía Costera}

A localização geográfica da região de La Araucanía encontra-se na costa oeste distante aproximadamente 30 quilômetros da capital regional. A região compreende os municípios Carahue, Puerto Saavedra, Teodoro Schmidt e Toltén. Faz fronteira ao norte com a região do Bío-Bío, ao sul com a região de Los Lagos. A área representa 10,2\% do total regional e corresponde a 165.993ha. A população total é de aproximadamente 66.450 habitantes. A distância até a capital regional, Temuco, varia conforme o município, mas em média é de cerca de $80 \mathrm{~km}$. 


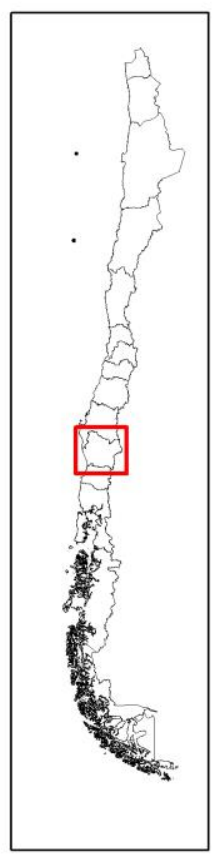

Projected Coordinate System WGS 1984 UTM Zone 18S

FIGURA 1 - MAPA LOCALIZAÇÃO DA REGIÃO DE LA ARAUCANÍA FONTE: Os autores.

\section{Caracterização social no contexto mapuche}

A Araucanía Costera é um território de ocupação essencialmente agrícola que em sua maioria corresponde a uma agricultura de subsistência. Além disso, devido aos costumes e às formações sustentadas por novos núcleos familiares, as terras do pequeno proprietário estão se reduzindo de forma extrema, sobrecarregando o recurso solo.

No ano de 2002, a região de La Araucanía sustentava uma população de 869.535 pessoas, das quais 281.127 moravam em áreas rurais. Aproximadamente 23,38\% delas pertencem ao povo mapuche. La Araucanía é a região do país com a maior quantidade de população mapuche. Enquanto no país os mapuche representam $4 \%$ da população total, na região de La Araucanía correspondem a 23,4\%. Sua presença é ainda mais alta nos municípios da costa dessa região, onde alcançam 39\% da população. Só no Carahue, de acordo com o censo de população e habitação executado no ano de 2002, a população mapuche correspondia a $29 \%$ do total da população do distrito. 


\section{Antecedentes físicos}

A Araucanía Costera corresponde aproximadamente a 10\% da nona região do Chile, a região de La Araucanía. Contém três subunidades principais de paisagem: cultivos de prados em plataformas costeiras, plantações florestais exóticas e planícies de uso agrícola. Sua principal característica física é a cordilheira da Costa ao norte da região, porém essa formação se vê interrompida na depressão intermediária entre as regiões de Puerto Saavedra e Teodoro Schmidt. No extremo norte, as maiores altitudes são cerca de 900 metros, que gradativamente vão sendo rebaixadas até a depressão para voltar a tomar altura no sul, no município de Toltén, conforme a Figura 2.
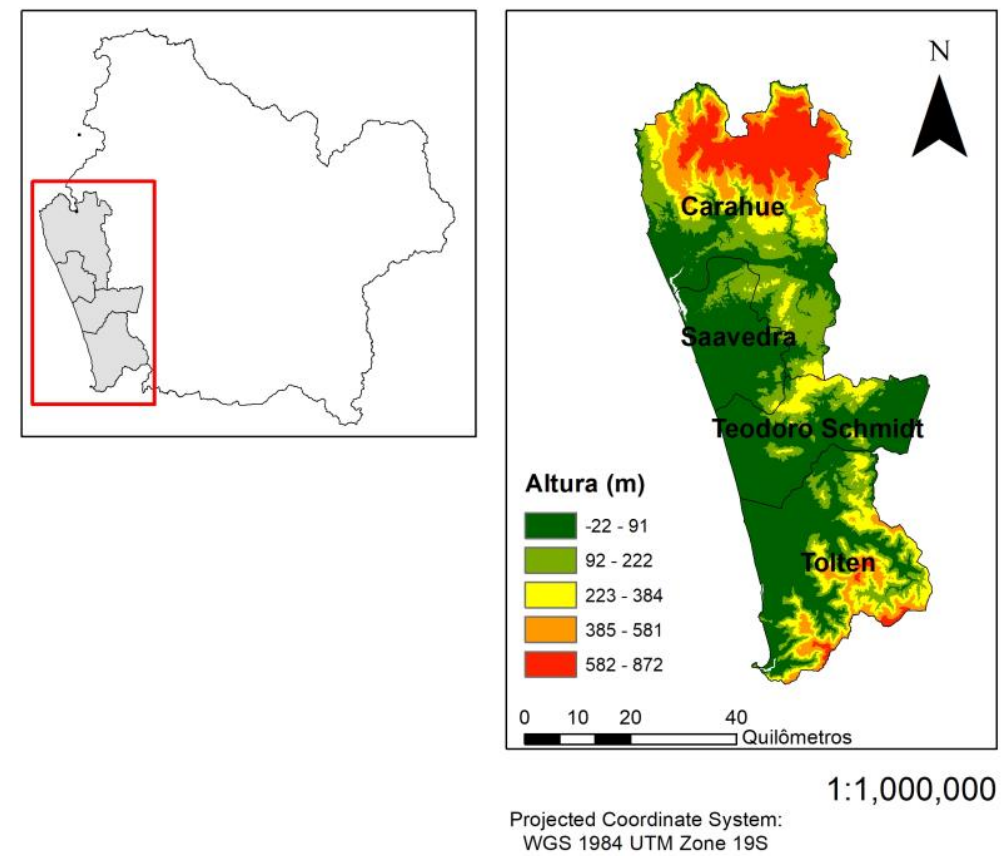

FIGURA 2 - ELEVAÇÃO DOS SOLOS NA REGIÃO DE LA ARAUCANÍA FONTE: Os autores.

O sistema agrário é um espaço de contato entre a cordilheira da costa e a depressão intermediária, modeladas pelas características do clima, do solo, da vegetação, da ação de agentes erosivos, dos sistemas fluviais e das atividades antrópicas, o que tem gerado uma grande diversidade na paisagem (MARDONES, 2005).

Segundo a Dirección Meteorológica de Chile, ao norte da região pesquisada se apresenta um clima de tipo temperado chuvoso com influência mediterrânea. A temperatura média anual em 
Carahue é de $10.3^{\circ} \mathrm{C}$. A precipitação é de $2.251 \mathrm{~mm}$ ao ano. Mais ao sul da região, em Toltén, predomina o clima temperado, com uma marcada presença das quatro estações do ano e uma temperatura média de 12 graus (PLADECO TOLTEN, 2005). O contraste é marcado entre o verão seco e com altas temperaturas e o inverno caracterizado por fortes e persistentes chuvas (1.500 a $2.000 \mathrm{~mm} / \mathrm{ano}$ ) concentradas entre os meses de maio a outubro, estimulando os processos de erosão hídrica (ENDLICHER, 1988; PEÑA-CORTÉS et al., 2005).

\section{Evolução e diferenciação dos sistemas agrários nos territórios mapuche na Araucanía Costera}

Depois de realizar a coleta de dados e uma extensa revisão bibliográfica, foram identificados quatro grandes sistemas agrários implementados nos diferentes territórios na região, desde o que se sabe de sua origem até os dias atuais. São eles: Sistema Agrário Indígena (até 1536); Sistema Agrário Pré-Colonial (1536 - 1883), Sistema Agrário Colonial (1883) e Sistema Agrário Atual (1973 - dias atuais). É importante salientar que os períodos de delimitação entre os distintos sistemas agrários são referências que não representam mudanças totais; são processos que ocorrem de forma diferenciada e em velocidades distintas no conjunto da região pesquisada. Apesar disso, procurou-se usar datas de eventos importantes como sinalizadores gerais da demarcação cronológica entre os sistemas.

\section{As incógnitas da pré-história}

Conforme pesquisas realizadas pela Fundación Monte Verde, existiriam registros históricos de depósitos humanos de 14.500 anos atrás, a aproximadamente $319 \mathrm{~km}$ ao sul de Araucanía Costera, o que até agora é considerado o assentamento humano mais antigo da América ${ }^{4}$. Esse fato evidencia a possível existência de vida humana na região em período anterior, o que é corroborado por publicações mais recentes no site oficial da Fundación Monte Verde, que relatam uma última escavação com objetos datados de até 18.500 anos atrás ${ }^{5}$.

\footnotetext{
${ }^{4} \mathrm{http}: / / \mathrm{www}$.latercera.com/noticia/tendencias/2013/11/659-553898-9-tras-26-anos-parte-nueva-excavacion-enyacimiento-monte-verde.shtml

${ }^{5}$ Sítio web: fundacionmonteverde.cl
} 


\section{Sistema Agrário Indígena (até 1536)}

Os primeiros colonos se depararam com uma região de abundantes recursos naturais. $\mathrm{Na}$ região, o período arcaico durou aproximadamente entre 7.000 a.C e 1.000 a.C. A floresta, a costa e a cordilheira foram os grandes mestres desses povos, que coexistindo com a natureza para as gerações, encontraram-se dispostos a experimentar uma grande mudança: a prática da horticultura. (ARANCIBIA e YAVAR, 1994; CONAMA, 2010).

A reconstrução do antigo passado indígena está repleta de dificuldades em função da imbricação entre a história e o mito ${ }^{6}$ (BENGOA, 1996, p. 12).

Conforme observa o historiador Diego de Rosales, a origem dos indígenas chilenos não é remontada por eles, para períodos anteriores aos do dilúvio, pois não compartilham memórias da criação e do princípio do mundo, nem dos homens (TORIBIO, 1882, p. 12). É por isso que a origem dos mapuche é relativamente incerta, e sobre ela foram formuladas numerosas hipóteses.

Conforme Bengoa (1996), existem algumas evidências de que em torno dos anos 600 a 500 a.C já existia uma cultura que pode ser referida de mapuche.

Diversos autores como Arancibia e Yávar (1994) postulam que La Araucanía possuía solos bastante férteis que permitiam aos indígenas a prática da agricultura com pequenas escalas de produção, em pequenas áreas de solos descobertos. Essas atividades eram desenvolvidas com ferramentas manuais de trabalho, excluindo o uso de metais, desconhecidos para esses povos nesse período. Apesar da pouca evidência, fala-se de ferramentas como o tridente de madeira de três pontas, enxadas e pá de pedra ou madeira.

Como afirma Toribio (1882), antes que viessem os espanhóis, os índios faziam seus instrumentos de pau, que chamavam luma (Amomyrtus luma), tinham outras madeiras muito duras também como o guayacan (Porlieria hygrometrica), o espino (Acacia caven), e o boldo (Pneumus boldus), que são madeiras que substituíam em muitos casos a falta de ferro.

$\mathrm{Na}$ época os mapuche baseavam sua dieta principalmente no pinhão; cultivavam principalmente para consumo produtos como batata e "porotos pallares" (uma espécie de feijão-branco) em solos descobertos e ou em terrenos de grande fertilidade. Além disso, complementavam sua dieta com a coleta de vegetais e moluscos oriundos da pesca, e praticavam a caça de camelídeos como o guanaco (Lama guanicoe) e veados nas áreas de floresta e campo (BENGOA, 1996). Ivan Inostroza assinala que a agricultura mapuche encontra-se consolidada

\footnotetext{
6 "Os mapuche povoaram a terra depois que houve uma grande enchente onde a água cobria os vales. Eles se salvaram sobre uma grande colina, em seguida, eles caíram e cobriram o território” (BENGOA, 1996, p. 12).
} 
desde a segunda metade do século XVIII com cultivos pré-hispânicos como o milho, quinoa, feijão, batatas, pimenta, entre outros (CORREA; MOLINA; YÁÑEZ, 2005, p. 43).

A organização social dessas comunidades era guiada pela busca da autossuficiência alimentar. Essa organização não estava baseada na hierarquização familiar e na divisão sexual do trabalho. Existem relatos que descrevem o trabalho agrícola como uma atividade familiar e social no qual todos trabalham arduamente igual para terminar o trabalho para, em seguida, desfrutar de uma festa com bebidas alcoólicas (BENGOA, 1996).

As contínuas chuvas do sul do Chile permitiram o desenvolvimento desses produtos. Isso explica a localização dos mapuche em terrenos pluviosos e a forma que transitavam da cordilheira ao mar para a coleta de seu alimento praticamente sem realizar intervenção e alteração na paisagem original. A data estabelecida para o final do sistema agrário indígena é 1536, aproximadamente no ano em que os espanhóis chegam a colonizar o sul do Chile, grande período de batalhas conhecido como a "Guerra de Arauco".

\section{Sistema Agrário Pré-colonial (1536 - 1880)}

Sem dúvida, as influências externas impactam e modificam culturalmente as populações receptoras. Apesar da forte resistência dos povos originários à invasão espanhola, é inegável que durante todo esse período existiu contato entre colonizadores e indígenas, que foram modificando paulatinamente o sistema agrário e sua organização social. É por isso que se descreve um segundo episódio no Sistema Agrário Indígena, nomeando-o pré-colonial, que abarca aproximadamente desde 1536, quando começa o período da colonização armada pelos espanhóis, até 1880, quando se realiza o último confronto mapuche (BND, 2016).

A população da região de La Araucanía, desde a chegada dos espanhóis, era de aproximadamente 500.000 habitantes organizados, que, sem dúvida, diminuiu em grande número depois da primeira rebelião mapuche, no ano de 1562 (BENGOA, 1996; BND, 2016). A chegada dos espanhóis interrompeu abruptamente a paz do povo mapuche na região e esses foram anos de intensas guerras e batalhas que, sem dúvida, alteraram fortemente o sistema completo da zona, e, por que não dizer, do país. Alguns autores denominam como a modificação territorial mais importante do Chile a perda dos territórios ao sul do Bío-Bío por causa da rebelião indígena do ano de 1598. Esse foi o fato que culminou em um complexo processo de ocupação espanhola na zona de La Araucanía, em que se definiu uma linha de fronteira que, em definitivo, dividiu por quase três 
séculos o país. Ao sul o território indígena e ao norte o território espanhol (ARANCIBIA; YABAR, 1994).

O século XVI é um período de datas importantes na história do país e, principalmente, da região. É importante destacar o denominado Pacto de Quillín ocorrido em 1641, no qual os espanhóis reconhecem o rio Bío-Bío como o limite norte do território mapuche (CORREA; MOLINA; YAÑEZ, 2005, p. 17; BND, 2016).

Os mapuche tinham conhecimentos técnicos sobre agricultura, pesca e caça. Conheciam a reprodução de certas espécies, como milho, quinoa (provenientes do Peru), abundante produção de batatas e produtos europeus, como trigo, cevada, ervilhas, linho, repolho. Tinham ferramentas e instrumentos limitados, mas estavam começando a criar gado (tinham criação principalmente para o autoconsumo de ovinos, guanacos e abundante caça de animais selvagens). Possuíam um nível de tecnologia agrária simples e primário conhecido como Rozatumba-quema o Roce, na qual se limpava o solo geralmente com fogo e as cinzas serviam de fertilizante para vários cultivos na mesma área (BENGOA, 1996; CORREA; MOLINA; YAÑEZ, 2005). Além disso, chama a atenção a rapidez com que os mapuche se apropriaram dos animais trazidos pelos espanhóis. Os cavalos multiplicaram-se facilmente nas pradarias férteis da Araucanía e ao final do século XVI os mapuche tinham mais cavalos do que todo o exército espanhol junto.

No século XVIII (1700-1800) diminuiu o ritmo das guerras e aumentaram os intercâmbios entre os mapuche e a sociedade espanhola (BENGOA, 1996), sendo esse o período de inclusão de novas ferramentas para a agricultura, de forma paulatina. A literatura descreve um comércio de intercâmbio de erva-mate e álcool. Assume-se baixa intervenção na paisagem original, já que principalmente os cultivos continuavam se realizando em solos descobertos.

Arancibia e Yávar (1994) consideram que esse foi um período de territórios férteis e extensos em relação à escassa população existente. Autores como Bengoa (1996) sugerem que a condição de um ecossistema com pouca disponibilidade de recursos naturais e o aumento da população humana pode ser um vetor que contribuiu para o desenvolvimento de uma agricultura intensiva.

O Estado chileno no ano 1825 subscreve com as autoridades tradicionais mapuche o Parlamento de Tapihue, através do qual reconhece a autonomia territorial mapuche. Entretanto, o Tratado de Tapihue reconhece a autonomia territorial mas inclui uma severa contradição que, finalmente, se traduz na perda de uma parte importante do território mapuche. Esta se refere à 
aplicação da norma da igualdade de direitos, o que significa que, na prática, durante a primeira metade do século XIX, a região de Araucanía Costera fora objeto de infiltração e usurpação de terras por parte dos chilenos denominadas "infiltración de la frontera", processo que se caracteriza pelo assentamento de chilenos no território mapuche como trabalhadores, arrendatários ou como proprietários de terras compradas fraudulentamente (CORREA; MOLINA; YÁÑEZ, 2005, p. 19).

Após o tratado de 1825, é promulgado o Decreto de março de 1853 que prescreve formalidades para conceder contratos sobre terrenos indígenas. Em síntese, entre 1830 e 1883 o Estado chileno ocupou a totalidade do território mapuche de La Araucanía, sendo que após a conclusão do processo de ocupação os vilarejos chilenos se consolidaram (CORREA; MOLINA; YÁÑEZ, 2005, p. 24). Ainda, a atividade agropecuária se limitava a uma exploração dos recursos; a economia chilena durante esse período (séculos XVII e XVIII) experimentou um crescimento e não um desenvolvimento (ARANCIBIA; YÁVAR, 1994, p. 52).

Até a metade do século XIX o povo mapuche gozava de autonomia territorial e em seus domínios o Estado chileno não exercia jurisdição efetiva (CORREA; MOLINA; YÁÑEZ, 2005, p. 17). Mas as mudanças políticas trouxeram consigo o aumento dos assentamentos humanos. Iniciouse a mudança do uso do solo, acelerando-se à medida que aumentava a densidade populacional e a produção econômica (CONAMA, 2010). Conforme Bengoa (1996), pode-se afirmar que em 1881 existia uma sociedade com uma economia mercantil muito desenvolvida e com setores agrícolas já constituídos, embora a agricultura não estivesse generalizada de forma homogênea em todas as regiões. Antes, existia pecuária de subsistência em pequena escala, destinada principalmente para o autoconsumo. Mas a pecuária, os equinos, as vacas e as ovelhas, trazidas pelos espanhóis, representavam a principal transformação na economia mapuche. O contato com a sociedade colonial do norte influenciou nos gostos e nos costumes araucanos, incorporando-se uma série de produtos provenientes do comércio.

A população mapuche tinha diminuído violentamente como resultado da guerra e da peste, ficando só um quinto da população inicial. Isso permitiu que as famílias ocupassem territórios maiores, onde se estabeleceram de forma mais estável, dedicando-se à criação de gado. E assim cada cacique começou a ter um lugar relativamente determinado, mesmo sem chegar à rigidez de um sistema de propriedade privada. No final do século XVIII, para instalar-se em um lugar despovoado, era necessário pedir permissão ao cacique mais próximo, considerado, de alguma maneira, senhor da terra. 
A introdução do comércio foi sem dúvida a consequência mais importante da atividade pecuária. A partir do século XVIII começou um ativo comércio fronteiriço que transformou a sociedade indígena. Trocavam-se mercadorias, vestimentas, artefatos, açúcar, erva-mate e álcool por animais.

\section{Sistema Agrário Colonial (1883 - 1973)}

Foram séculos de guerras, conflitos, batalhas, contatos, comércio e intercâmbios entre a população indígena e os espanhóis. A sociedade mapuche foi modificando sua economia, sua organização social e política, seus costumes em sua forma mais profunda. A sociedade mapuche no século XIX era uma organização dinâmica golpeada por profundas transformações.

Ao final do século XVIII e começo do XIX não existia um conceito de dinheiro como valor de câmbio; o dinheiro era a prata, que serviu para o intercâmbio, mas que também, e principalmente, tinha o uso em si mesmo como metal precioso para a fabricação de joias.

A introdução da agricultura se configurou em uma grande mudança econômica e social, em especial o cultivo de cereais, que implicou na preparação dos solos e realização de tarefas mais complexas.

O trigo foi um dos primeiros alimentos apropriados ao começo da ocupação (primeiro século surge a farinha torrada como alimento), os cultivos das fazendas cresceram em tamanho e arados simples começaram a ser usados. O crescimento e desenvolvimento da agricultura no século XVIII, e sobretudo no século XIX, levou a uma situação de crescente diferenciação social do trabalho, aproximando-se o sistema a uma forma germinal de trabalho semiassalariado. Na metade do século XVIII há relatos confirmando que a produção da agricultura e o sistema de organização do trabalho voltaram-se aos cultivos abundantes de milho e batata, cultivo de favas e ervilhas em quantidades moderadas e ao cultivo de trigo em baixas quantidades. Durante esse período começa a diferenciação do trabalho, como o costume de preparar e de semear primeiro a terra do Lonco ${ }^{7}$. O mesmo ocorreu nas atividades do cuidado das plantações e, sobretudo, nas colheitas.

Esse sistema agrário também é caracterizado pela intensificação da urbanização, transformando o rural no continuum do urbano, e pela consequente ampliação da tecnificação e presença da pluriatividade. É também o período em que se fundam as principais cidades da

\footnotetext{
${ }^{7}$ Lonco (Lonko, cacique, nillatufe, o cabeça da comunidade) é a autoridade fundamental da cultura mapuche. É um cargo com conotações administrativas e religiosas.
} 
Araucanía Costera. Nesse mesmo período também houve um aumento nas tecnologias e nos meios de transportes para conectar a zona com o resto do país. Mais especificamente no ano de 1912 se formaram as ferrovias entre a capital e o sul do Chile (ARANCIBIA; YÁVAR, 1994).

O período pré-industrial (aproximadamente de 1930 a 1950) foi o período que se caracterizou pelo desenvolvimento das capacidades para o uso da madeira serrada, o uso do floreio e a ocupação e exploração ilegal das reservas florestais do Estado (CONAMA, 2010).

\section{Sistema Agrário Atual (desde 1973 até hoje)}

Foram mais de quatrocentos anos de contatos, guerras, acordos políticos e estabilizações sociais que transformaram profundamente o sistema agrário na Araucanía Costera. A dinâmica estabelecida partiu de uma sociedade basicamente caçadora, coletora, com uma simples organização familiar, dando lugar a uma sociedade agrícola de produção de gado, com crescentes relações mercantis, com um sistema de trabalho cada vez mais complexo, necessidade de aumentar a relação com a sociedade chilena e, portanto, com uma organização social em constantes processos de transformação.

A configuração do sistema agrário atual só pode ser adequadamente entendida nesse contexto de mudanças, sensivelmente marcado pelo processo de modernização da agricultura e ampliação da mercantilização. A introdução da modernização da agricultura com a generalização das máquinas, equipamentos, insumos químicos e sementes se efetiva no início desse período. Não se pode deixar de mencionar o papel do Estado chileno, que atuou intensamente nas décadas de 1970 e 1980 utilizando mecanismos de fomento, crédito agrícola, extensão rural e a política de preços, todas essas mudanças realizadas durante o período da ditadura militar ${ }^{8}$. Esse tripé permitiu a implementação da revolução verde, considerada como a segunda revolução da agricultura, promovendo o processo de modernização da agricultura (PACIFICO, 2009), o qual implementou transformações drásticas ao território mapuche.

Na atualidade, o município de Carahue, em termos gerais, define-se com uma economia eminentemente agrícola com forte componente de subsistência. Até o ano de 2009, havia grandes extrações de produtos marítimos como choro maltón e chorito (quilmahue), os quais chegaram a

\footnotetext{
${ }^{8}$ Os acontecimentos da década de 1970 introduziram no Chile uma profunda crise econômica e política. Nesse contexto extraordinariamente complexo, os problemas que enfrentava a agricultura se aprofundaram ao ponto da crise agrícola ter adquirido sua máxima expressão. Durante o golpe militar se ditaram normas tendentes a fomentar o monocultivo de espécies arbóreas, sendo chamado de reflorestamento artificial (D.L N' 701 de 1974) (ARANCIBIA; YÁVAR, 1994, p. 191-192).
} 
cerca de $90 \%$ do total da região de La Araucanía. Além disso, no ano de 2010 essa percentagem diminuiu fortemente para $11 \%$. Hoje, os cultivos de maior envergadura são as plantações de monocultivos arbóreos, os cereais e os tubérculos (com 18.726 ha, 3.750 ha e 2.352 ha, respectivamente). A respeito dos distintos produtos agropecuários explorados no território se observa a categoria de frutas, hortaliças e verduras em detrimento de hortas caseiras. Em relação à exploração animal, encontramos bovinos, porcos, ovinos, cavalos, caprinos e lagomorfos (coelhos, lebres) (PLADECO CARAHUE, 2013).

Do mesmo modo, em Puerto Saavedra desenvolve-se uma agricultura de subsistência em que se destaca a produção de batatas e grãos menores, ervilhas, grãos, feijão verde e lentilhas. A partir do ponto de vista florestal, se destacam plantações de espécies exóticas de rápido crescimento como o pino insigne e os eucaliptos. Nessa comunidade, a pesca é praticada com embarcações e técnicas artesanais de trabalho, sendo que $30 \%$ dos recursos pesqueiros são destinados à comercialização e o restante ao autoconsumo familiar (PLADECO PUERTO SAAVEDRA, 2013).

Em relação a Teodoro Schmidt, o principal uso do solo está relacionado à pecuária, pois as pradarias nativas representam 41,2\% do total, além das pradarias melhoradas. Mas há também atividades importantes no âmbito agrícola relacionadas aos cereais, tubérculos e cultivos industriais, sendo os principais batata, trigo branco, aveia, lupinos (Lupinus polyphyllus) e cevada cervejeira. $\mathrm{O}$ mais notável nesses cultivos é a quantidade de hectares com cultivo de batata, representando 25,3\% do total dos cultivos na região de La Araucanía. Segundo a literatura, os usos de solo que mais cresceram em Teodoro Schmidt, entre os anos 1997 e 2007, foram as plantações com espécies exóticas, que quase duplicaram (PLADECO TEODORO SCHMIDT, 2008).

Em Toltén, as principais atividades econômicas são a agrícola, produção de gado e florestal, ressaltando também a pesca artesanal nas localidades de Queule e Barra. Os tipos de cultivos produzidos nesse município correspondem principalmente a pradarias (2.400 ha), batatas (2.150 ha), cereais como aveia (400 ha) e trigo (390 ha) (PLADECO TOLTEN, 2005).

Como se pode observar, a transformação da paisagem na região estudada ocorreu desde a pré-história e continua ocorrendo até hoje com um intenso desmatamento. Mas o período industrial se caracteriza pela substituição do bosque nativo e pelos monocultivos arbóreos para o fornecimento de madeira. Finalmente, a indústria florestal cresceu, modernizou-se e passa a ser a principal atividade industrial do país (CONAMA, 2010). E assim se instaura um contexto de empobrecimento, estagnação e degradação pela invasão das florestas na região, fazendo com que 
muitos agricultores optassem por migrar para a cidade nos últimos anos, os mais jovens especialmente, com a intenção de buscar novos espaços para viverem e oportunidades na cidade (CONAMA, 2010).

\section{Transformações da cobertura vegetal da região de La Araucanía}

Quando os colonizadores espanhóis chegaram à Araucanía Costera havia uma cobertura vegetal quase completa, formada por densos bosques e matas. Dessa situação original mantiveram-se alguns remanescentes relativamente representativos, coexistindo associações vegetais nativas com comunidades secundárias em diferentes estados de regeneração e de perturbação, o que na atualidade constitui uma paisagem muito diversificada (CONAMA, 2010). O bosque de Coigüe (Nothofagus dombeyi) e Ulmo (Eucryphia cordifolia), localizado na vertente oriental da Cordilheira da Costa, encontra-se muito diminuído por ser amplamente substituído por plantações de pino insigne (Pinus radiata), já que essa espécie exótica encontra condições ótimas para o crescimento das populações nessa zona. Além disso, esse bosque tem sido desmatado por madeireiros ou substituído por prados, que foram dominados por ervas invasoras trazidas da Europa, que se degradam facilmente pelo pisoteio e pastoreio excessivo, gerando condições de solo que invadem o matagal de espinillo (Ulex europaeus) (CONAMA, 2010).

Na depressão intermediária, o principal bosque substituído foi o Roble-Laurel-Lingue que se distribuía na região. Esse bosque ocupava solos de boa capacidade agroecológica, pelo que tem sido amplamente substituído para o uso agrícola e para a criação de gado (CONAMA, 2010). Na atualidade, o mais frequente é encontrar o tipo florestal Roble Rauli Coigue. De acordo com a Figura 3, identifica-se a variação do bosque nativo na região de Araucanía Costera, a partir dos anos 1973, 1999 e 2008, corroborando com os relatos da literatura referentes à destruição massiva dos bosques, a qual intensificou-se dramaticamente nos dois últimos decênios do século XX. 

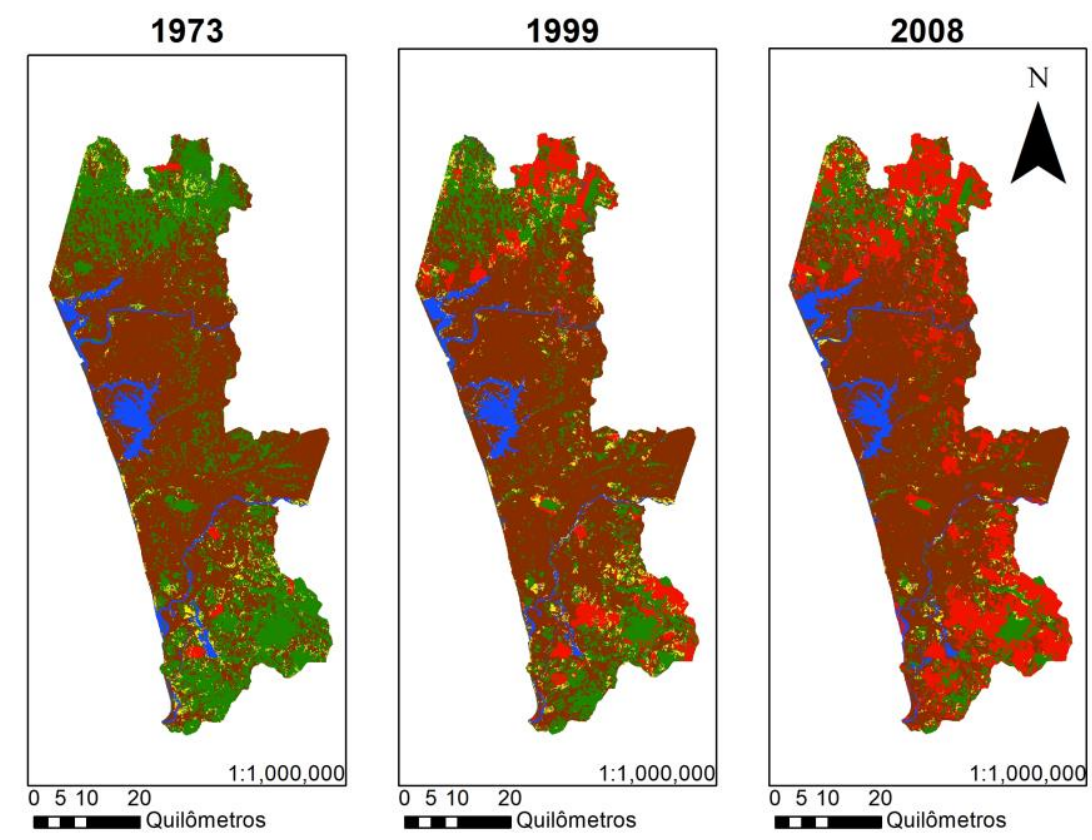

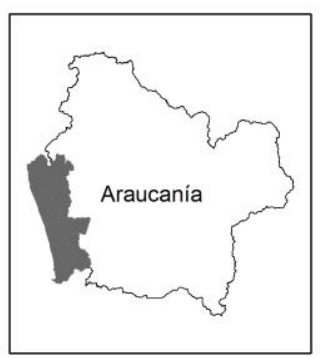

Simbologia

Uso do solo

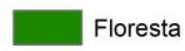

$\square$ Capoeira-Mato

Plantações florestais

Áreas agrícolas

Corpos de água

Áreas não cultivadas

Projected Coordinate System: WGS 1984 UTM Zone $19 S$

FIGURA 3 - TRANSFORMAÇÕES DO USO DO SOLO NA ARAUCANÍA COSTERA NAS DÉCADAS DE 1970 A 2010

FONTE: Os Autores.

A análise da cobertura vegetal dos mapas evidencia que entre os anos 1973 e 2008 se perderam 58.198 ha de floresta nativa, o equivalente a $62 \%$ da cobertura florestal existente. As áreas agrícolas e a água também diminuíram aproximadamente 5\% da superfície. Por outro lado, os monocultivos arbóreos aumentaram 68.115 hectares em quatro décadas. Esse aumento representa 21,68\% do território, que deixou de ser floresta, capoeira-mato, áreas agrícolas e corpos de água para se tornarem monocultivos arbóreos de espécies exóticas.

$\mathrm{Na}$ imagem observa-se uma rápida mudança de cobertura do solo ocorrido desde 1973 a 2008. O aumento da taxa de perda de floresta ao longo do tempo é preocupante porque, em geral, o padrão aponta para um processo de homogeneização da paisagem, sendo os monocultivos arbóreos os cultivos que se espalharam em grandes áreas geográficas, tornando-se a cobertura dominante da terra. Os resultados da análise das imagens coincidem com os do estudo de Miranda (2015), apresentado na Figura 4, que evidenciam que os monocultivos arbóreos aumentaram nas zonas costeiras, do vale central e na montanha pré-andina. 


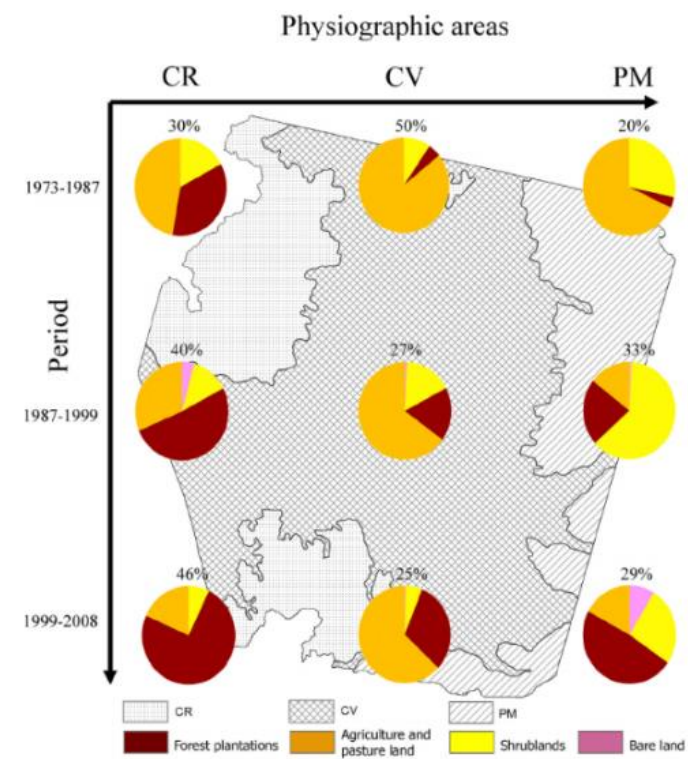

FIGURA 4 - PROPORÇÃO DE FLORESTAS NATIVAS SUBSTITUÍDAS POR DIFERENTES USOS DO SOLO E COBERTURA EM DIFERENTES PERÍODOS E ÁREAS FISIOGRÁFICAS

FONTE: MIRANDA et al. (2015).

LEGENDA: CR: Faixa litorânea; CV: Vale central; PM: Montanha Pré-Andina.

\section{Conclusões}

O objetivo deste artigo foi apresentar sucintamente os aspectos chaves para a compreensão da evolução e diferenciação dos sistemas agrários que se desenvolveram nos territórios mapuche na região da Araucanía Costera. Assim, foram identificados quatro grandes sistemas agrários em um período que se estende por mais de 9000 anos. Cabe destacar que os anos de delimitação entre os distintos sistemas agrários identificados são referências cronológicas e não representam uma mudança absoluta e imediata, visto que isso ocorre de forma diferenciada e em velocidades relativamente distintas no conjunto da região de estudo. São processos históricos, que não seguem rigorosamente as delimitações cronológicas, todavia elas representam sinalizações de mudanças substantivas e relativamente generalizadas. Além disso, ocorrem interpenetrações e sombreamento entre os distintos sistemas agrários.

Esses sistemas foram marcados pela complexidade das dinâmicas sociais que se desenvolveram no tempo e no espaço. É importante referir-se ao processo de constituição da propriedade mapuche. Esta se caracteriza pela redução territorial desde a chegada dos espanhóis, e logo com a expansão das plantações exóticas, que por incentivos meramente econômicos passam a 
se converter na principal cobertura da paisagem em grande parte da zona pesquisada que transformou o sistema de vida completo desse povo indígena, de uma economia agrícola em expansão a um sistema agrário de subsistência, e mesmo de resistência na atualidade.

No período atual, ocorreram as maiores transformações nos territórios mapuche, onde o desenvolvimento do setor florestal na região se configurou como uma forma de invasão e expropriação do território indígena. A condição que os territórios mapuche estão expostos na atualidade evidencia a complexidade do confronto entre a possibilidade de reprodução social dos mapuche com uma política que não só se expressa em milhões de indivíduos de Pinus sp, que ganham a cada dia espaço nos territórios no sul do Chile e se caracterizam como soldados verdes dos principais grupos econômicos do país, como também são a expressão de uma política neoliberal que procura se estabelecer como o modelo de desenvolvimento da Araucanía Costera.

\section{Referências}

ARANCIBIA, P.; YÁVAR, A. La agronomía en la agricultura chilena. Santiago: Colegio de ingenieros agrónomos, 1994.

BENGOA, J. Historia del pueblo mapuche (Siglo XIX y XX). 5. Ed. Santiago: Ediciones Sur, 1996. Disponível em: <https://creandopueblo.files.wordpress.com/2011/08/bengoahistoriapueblomapuche.pdf>. Acesso em: jul. 2016.

BIBLIOTECA NACIONAL DE CHILE (BND). La familia mapuche (1536-1900). Memoria Chilena. Disponível em: <http://www.memoriachilena.cl/602/w3-article-689.html\#cronologia>. Acesso em: jul. 2016.

COMISIÓN NACIONAL DE MEDIO AMBIENTE (CONAMA). MINISTERIO DE EDUCACIÓN. CENTRO DE ESTUDIOS AGRARIOS Y AMBIENTALES (CEA) liderado por el académico Andrés Muñoz. Educación Ambiental Región de La Araucanía. CD-ROM.Disponível em: 〈http://www.sinia.cl/1292/printer-29101.html>. Acesso em: jul. 2016.

CORREA M.; MOLINA, R.; YÁÑEZ, N. La Reforma Agraria y las tierras mapuches Chile 1962-1975. Santiago: Lom ediciones, 2005.

DONOSO, C.; LARA, A. Utilización de los bosques nativos en Chile: pasado, presente y futuro. In: ARMESTO, J.; VILLAGRÁN, C.; KALIN, M. (Editores). Ecología de los bosques nativos de Chile. Santiago de Chile: Editorial Universitaria, 1997. p. 363-387.

ENDLICHER, W. El Problema de la Erosión del Suelo en la Cordillera de la Costa de la Octava Región. Revista de Geografía Norte Grande, n. 15, p. 11-27, 1988. 
MIGUEL, L. (Org.) Dinâmica e diferenciação de sistemas agrários. Porto Alegre: Editora da UFRGS, 2010. 72 p. (Série Educação a Distância). Disponível em: <http://www.ufrgs.br/cursopgdr/downloadsSerie/SistemasAgrarios.pdf>. Acesso em: abr. 2018.

MIRANDA, A.; ALTAMIRANO A.; CAYUELA L.; PINCHEIRA F.; LARA A. Different times, same story: native forest loss and landscape homogenization in three physiographi calareas of south-central of Chile. 2015.2 Disponível em: <https://www.researchgate.net/publication/273770360_Different_times_same_story_Native_forest_ loss_and_landscape_homogenization_in_three_physiographical_areas_of_south-central_of_Chile>. Acesso em: jul. 2016.

PACIFICO, D. história da modernização da agricultura: um conto de muitas facetas. In: DAL SOGLIO, F.; KUBO, R. (Orgs.). Agricultura e sustentabilidade. Porto Alegre: Editora da UFRGS, 2009. 72 p. (Série Educação a Distância). Disponível em: <https://moodle.ufrgs.br/pluginfile.php/2432812/mod_resource/content/1/Agricultura\%2C\%20Sust entabilidade.pdf >. Acesso em: mar. 2018.

PLAN DE DESARROLLO COMUNAL (PLADECO) CARAHUE. 2012-2017. Enero 2013. PAC Consultores Ltda.

PLAN DE DESARROLLO COMUNAL (PLADECO) PUERTO SAAVEDRA. 2014-2018 Diciembre, 2013. Disponível em: <http://www.transparencialocal.cl/saavedra/documentos/transparencia439.pdf>. Acesso em: jul. 2016.

PLAN DE DESARROLLO COMUNAL (PLADECO) TEODORO SCHMIDT. Ejecutado por: Universidad de La Frontera, Instituto de Desarrollo Local y Regional, Ider. Diciembre 2008. Disponível em: <www.ider.cl/docs/info_19.pdf>. Acesso em: jul. 2016.

PLAN REGULADOR COMUNAL TOLTÉN. 2005-2015.

MARDONES, M. La cordillera de la Costa: caracterización físico-ambiental y regiones morfoestructurales. In: SMITH-RAMÍREZ C.; ARMESTO, J.; VALDOVINOS, C. Historia, biodiversidad y ecología de los Bosques Costeros de Chile. Santiago de Chile: Editorial Universitaria, 2005. p. 39-59.

MAZOYER, M.; ROUDART, L. História das agriculturas no mundo: do neolítico à crise contemporânea. São Paulo: UNESP; Brasília: NEAD, 2010.

PEÑA-CORTÉS, F.; BERTRÁN, C.; SCHLATTER, R.; HAUENSTEIN, E.; DURÁN, T.; TAPIA, J. Proyecto Fondecyt 1030861 Análisis Integrado del Borde Costero de la IX Región. Propuestas y Criterios para la Planificación Ecológica de sus Humedales. Concepción: Informe de Avance, 2005. 
RIOSECO, R.; NARANJO, G.; HENRÍQUEZ, M. Sistemas agrarios de Chile. Instituto de Geografía. Pontificia Universidad Católica de Chile. Disponível em: <www.uc.cl/sw_educ/geografia/sistemas agrarios de Chile>. Acesso em: jul. 2016.

TORIBIO MEDINA, J. Los aboríjenes de Chile. Santiago: Imprenta Gutenberg, 1882.

Artigo recebido em 09/04/2018. Aceito para publicação em 20/07/2018. 